Provided for non-commercial research and education use. Not for reproduction, distribution or commercial use.

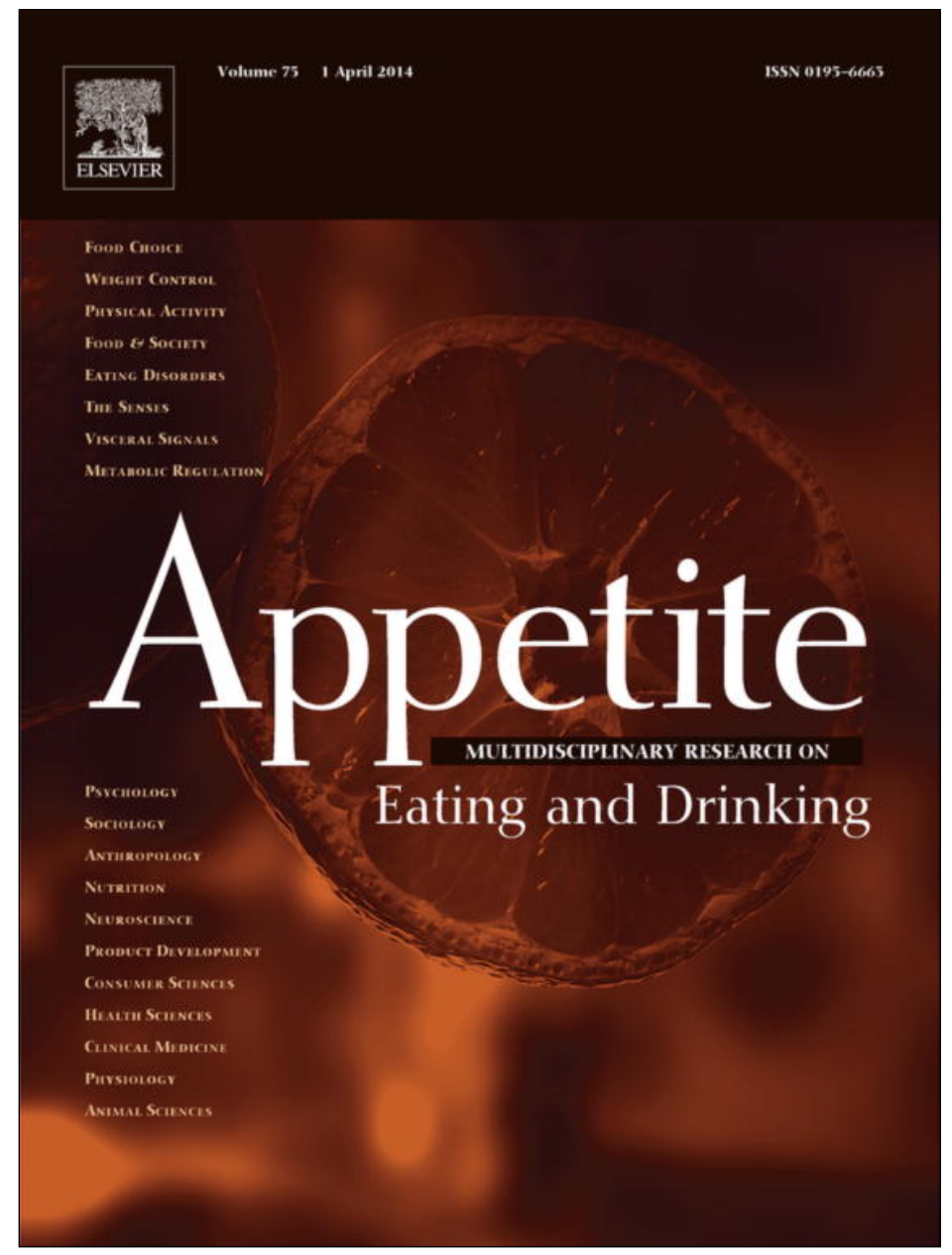

This article appeared in a journal published by Elsevier. The attached copy is furnished to the author for internal non-commercial research and education use, including for instruction at the authors institution and sharing with colleagues.

Other uses, including reproduction and distribution, or selling or licensing copies, or posting to personal, institutional or third party websites are prohibited.

In most cases authors are permitted to post their version of the article (e.g. in Word or Tex form) to their personal website or institutional repository. Authors requiring further information regarding Elsevier's archiving and manuscript policies are encouraged to visit:

http://www.elsevier.com/authorsrights 
Research report

\title{
A brief mindfulness intervention reduces unhealthy eating when hungry, but not the portion size effect ${ }^{\text {is }}$
}

\author{
David Marchiori ${ }^{\text {a,* }}$, Esther K. Papies ${ }^{\mathrm{b}}$ \\ ${ }^{a}$ Department of Social Psychology, Tilburg University, Warandelaan 2, P.O. Box 90153, 5000 LE Tilburg, The Netherlands \\ ${ }^{\mathrm{b}}$ Department of Social and Organizational Psychology, Utrecht University, The Netherlands
}

\section{A R T I C L E I N F O}

\section{Article history:}

Received 25 October 2013

Received in revised form 6 December 2013

Accepted 15 December 2013

Available online 20 December 2013

\section{Keywords:}

Portion size effect

Intervention

Mindfulness

Body scan mediation

Hunger

Internal and external cues of eating

\begin{abstract}
A B S T R A C T
Objective: The present research examined the effects of a mindfulness-based intervention to foster healthy eating. Specifically, we tested whether a brief mindfulness manipulation can prevent the portion size effect, and reduce overeating on unhealthy snacks when hungry. Methods: 110 undergraduate participants $\left(M_{\mathrm{Age}}=20.9 \pm 2.3 ; M_{\mathrm{BMI}}=22.3 \pm 2.5\right)$ were served a small or a large portion of chocolate chip cookies after listening to an audio book or performing a mindfulness exercise (i.e., body scan). Current level of hunger was assessed unobtrusively on a visual analog scale before the eating situation. Main outcome measure: Calorie intake from chocolate chip cookies. Results: When presented with a large compared to a small portion, participants consumed more cookies ( $+83 \mathrm{kcal})$. This was not affected by the mindfulness intervention or by hunger. However, while control participants ate more unhealthy food when hungry than when not hungry $(+67 \mathrm{kcal})$, participants in the mindfulness condition did not $(+1 \mathrm{kcal})$. Conclusions: Findings confirm the prevalence and robustness of the portion size effect and suggest that it may be independent from awareness of internal cues. Prevention strategies may benefit more from targeting awareness of the external environment. However, mindfulness-based interventions may be effective to reduce effects of hunger on unhealthy food consumption.
\end{abstract}

(c) 2013 Elsevier Ltd. All rights reserved.

\section{Introduction}

Many Western societies face rising numbers of overweight and obesity (WHO, 2010), a phenomenon that may be due to a positive food intake balance of less than 50 calories a day (Hill \& Peters, 1998). The ubiquitous availability of tasty high-energy foods, especially snacks, has been recognized as a main contributor to this imbalance and hence the obesity epidemic. The mere presence of attractive high-calorie foods can make it difficult to resist them (Wansink, Painter, \& Lee, 2006), even for people who are chronically concerned with controlling their weight (Papies \& Hamstra, 2010; Papies, Potjes, Keesman, Schwinghammer, \& van Koningsbruggen, in press; Papies \& Veling, 2013). Merely perceiving attractive food triggers spontaneous simulations of eating it, including thinking about the taste, texture, and pleasure of eating the food (Papies, 2013), and it activates brain areas for taste and reward as if one were actually eating the food (e.g., Simmons, Martin, \& Barsalou,

Acknowledgements: We would like to thank MadelijnStrick for lending her voice for the audio recording of the body scan. This work was supported by a grant from the National Research Fund, Luxembourg (07/052) to David Marchiori, and a grant of the Netherlands Organization for Scientific Research (NWO VENI 451-10-027) to Esther K. Papies.

* Corresponding author.

E-mail address: D.R.marchiori@uvt.nl (D. Marchiori).
2005). These simulations of eating and the associated pleasure can trigger approach behavior (Papies, Barsalou, \& Custers, 2012), and thus interfere with long-term goals of weight control.

Importantly, not only the availability, but also the portion size of high-calorie snacks has increased considerably over the past 30 years (Piernas \& Popkin, 2010). This is highly problematic, as we tend to eat more food out of large than small portions, without compensating for this excess intake in subsequent meals - the socalled portion size effect (for a review see Wansink, 2004). The present research was designed to test a novel intervention strategy to prevent these effects of food temptations to eating behavior.

Research on the mechanisms underlying the portion size effect suggests that the size of the available portion works as an external cue of how much is appropriate to eat, which then determines intake (Wansink, 2004). Such external cues are especially powerful because consumers in industrialized societies are usually in a "zone of biological indifference", with little awareness of internal cues of hunger and satiety (Herman \& Polivy, 2005). Portion size cues are so strong that they even override our own needs and preferences: in a study by Wansink and Kim (2005), participants increased their intake by $33.6 \%$ when offered a larger food container (i.e., 240 vs. $120 \mathrm{~g}$ ), despite the fact that the food was stale (i.e., 14 days old popcorn), and even though many of the participants had just eaten lunch (Wansink, 2006). Hence, we suggest 
that helping consumers to be aware of and rely on internal signals of hunger and satiety might reduce the influence of external cues and lead to healthier eating. We test whether this can be achieved by a mindfulness-based intervention.

Mindfulness can be defined as an open, nonjudgmental attention to one's present-moment experiences, including one's behaviors, bodily sensations, thoughts and feelings (Bishop et al., 2004). One of the crucial training components in mindfulness programs is the body scan exercise, which trains participants to move their attention calmly to the different parts of their body, and to notice and accept the sensations they experience in an open and nonjudgmental way. This "mindful" perspective on one's own experiences, which participants are instructed to adopt during the body scan, has been shown to reduce impulsive responding to external stimuli, and to the thoughts that they trigger (Papies et al., 2012). Research on the body scan has shown that this increases awareness of internal cues (Alberts, Thewissen, \& Raes, 2012), including cues of satiety and hunger (Kristeller \& Wolever, 2010; Van de Veer, vanHerpen, \& van Trijp, 2012). It also increases participants' tendency to compensate for the intake of unhealthy food by eating less unhealthy food later (Van de Veer et al., 2012). Here we suggest that this mindfulness exercise may reduce the degree to which we rely on external cues, such as portion size, when deciding how much to eat of an unhealthy snack, and as a result reduce the portion size effect.

An important internal cue that affects eating is the experience of how hungry we feel. Hunger typically boosts the perceived attractiveness especially of high-calorie foods (Lozano, Crites, \& Aikman, 1999; Siep et al., 2009), leads to automatic approach responses (Seibt, Häfner, \& Deutsch, 2007), and increases choices and intake of unhealthy, but not healthy food (Papies, Pronk, Keesman, \& Barsalou, in preparation). Thus, on the one hand, when awareness of internal cues increases, intake of unhealthy food may be higher when participants are hungry compared to when they are not hungry. On the other hand, however, recent research in eating behaviors has shown that mindfulness-based interventions can eliminate impulsive reactions toward unhealthy food (Hamilton, Fawson, May, Andrade, \& Kavanagh, 2013; Papies et al., 2012), lead to healthier food choices (Dalen et al., 2010) and decrease actual intake of unhealthy food when hungry (Papies et al., in preparation). In order to test these competing hypotheses, we included a measure of hunger in the current study and examined how a mindfulness-based intervention affects the impact of hunger on the consumption of chocolate chip cookies as an afternoon snack.

\section{Method}

\section{Participants}

Participants were a convenience sample of students of Tilburg University who received course credit or $€ 8$ for participation. Three participants were excluded for reporting falling asleep and four for reporting they thought they might have fallen asleep (all in the body scan condition), three for not following all the instructions and one because of a cookie allergy, resulting in a sample of 110 students $\left(M_{\mathrm{Age}}=20.9 \pm 2.3 ; M_{\mathrm{BMI}}=22.3 \pm 2.5\right)$. Power analysis shows that with an effect size of 0.25 and an alpha level of 0.05 , we needed a total sample of 95 participants (approximately 24 participants per condition) to obtain a power of 0.8 (Cohen, 1988).

\section{Design}

The study used a 2 (Portion size: small vs. large) $\times 2$ (Intervention: control vs. body scan) between-subjects design, with selfreported hunger as an additional continuous variable. Participants were assigned to conditions based on a Latin square randomization: small portion - audio book $(n=25,5$ male), small portion body scan ( $n=30,11$ male), large portion - audio book $(n=30,9$ male) and large portion - body scan ( $n=25,7$ male). The study was approved by Tilburg University's Ethics committee.

\section{Portion size and foods}

Participants were served two types of chocolate chip cookies (Choc chip mini's, Verkade, Zaandam, Netherlands and Prince Mini Stars, Kraft Foods/Lu, Northfield, Illinois, US), which were chosen as the afternoon snack based on a pilot study $(N=10)$. Portion size was based on national data regarding average intake amount of cookies during an afternoon snack (i.e., $30 \mathrm{~g}$, Dutch National Food Consumption Survey 2007-2010). This amount was increased to determine the small portion, so that intake would not be artificially limited to the amount initially served. Thus, the small portion weighed $51 \mathrm{~g}$ ( $247.5 \mathrm{kcal}$ ) and contained 10 cookies, five of each type. The large portion was three times as large ( $153 \mathrm{~g}, 30$ cookies, $742.5 \mathrm{kcal})$. Cookies in both conditions were served on a white plastic plate. All participants were served the same amount of water $(15 \mathrm{cl})$ in a plastic cup. Food and beverage intake were assessed with a food scale and computed by subtracting intake from amount served (within $1 \mathrm{~g}$; Digital Kitchen Scales, Brabantia). Amount of food consumed was operationalized as calorie intake, obtained by converting amount of grams consumed into kcal according to the manufacturer's package information. None of the participants asked for a refill (water or cookies).

\section{Intervention}

Participants listened to the introduction of the audio book "The Digital Fortress" by Dan Brown (i.e., the first $14 \mathrm{~min}$ ) or to the body scan, a typical mindfulness exercise. The book was chosen because it is unrelated to body-, weight- or food-specific themes. The body scan meditation instructions were created according to the typical structure of a body scan (Cropley, Ussher, \& Charitou, 2007) and written by the authors based on a synthesis of body scan instructions. This exercise guides attention to the different parts of the body and instructs participants to simply observe all sensations in an open and nonjudgmental way. Importantly, no mention was made of mindfulness or meditation. The instructions were paced such that participants had ample time to move their attention to the various body parts and observe their thoughts and body sensations in a nonjudgmental manner. The body scan lasted $14 \mathrm{~min}$. in total, and was read by a female voice and recorded digitally. The clarity of the body scan instructions was tested in a pilot study $(N=33)$.

\section{Procedure}

The study was advertised as two different experiments, but did not mention mindfulness or snacking. It took place between 2 and $5 \mathrm{pm}$, and lasted approximately $45 \mathrm{~min}$. Upon arrival, participants were seated in individual cubicles. They were asked to put on headphones and to follow the instructions on their computer screen. Depending on condition, they listened to the audio book or to the instructions for a body scan exercise. Then participants answered questions about their mood and the audio recording to support the cover story (i.e., study on information processing). These questions were also used to unobtrusively include a measure of their current levels of hunger and thirst (on visual analog scales, Marchiori, Waroquier, \& Klein, 2011).

Next, the experimenter started what was presented as the next experiment (i.e., a study on consumer experience). Participants were served a glass of water and a plate containing two types of 
Table 1

Means, standard deviations and correlations of food-related and participant characteristics.

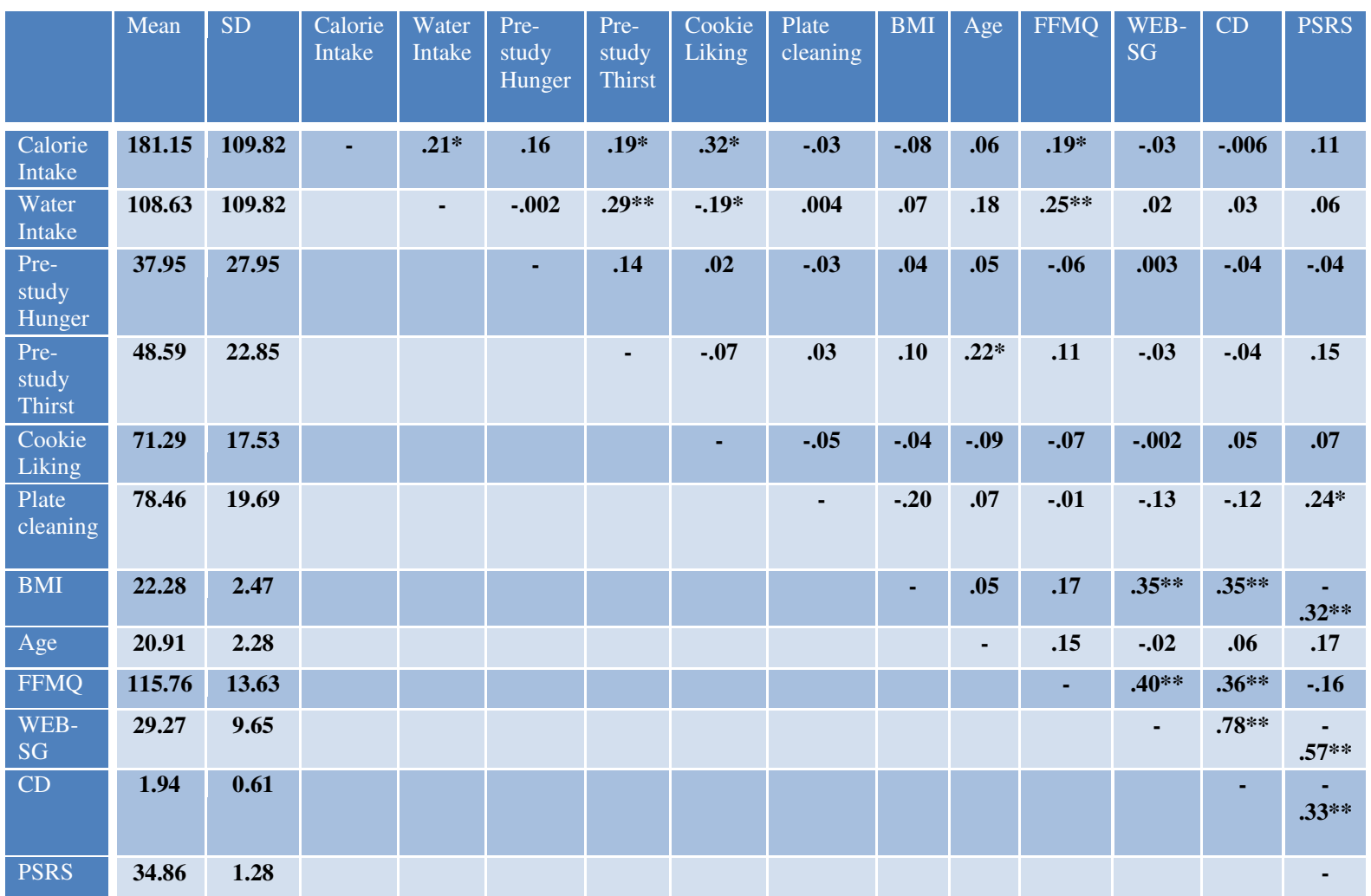

SD refers to standard deviation; Calorie intake refers to the number of calories of cookies consumed; Water intake refers to the number of centiliters of water consumed; prestudy hunger, pre-study thirst, cookie liking and plate cleaning were assessed on visual analog scales ranging from 0 to 100; BMI refers to Body Mass Index; FFMQ refers to the Five Factor Mindfulness Questionnaire; WEB-SG refers to the Weight- and Body-Related Shame and Guilt scale; CD refers to the concern for dieting measure of the Restraint Scale; PSRS refers to the Perceived Self-Regulatory Success scale. Asterisks indicate significance at an alpha level of .01 for two asterisks and .05 for one.

chocolate chip cookies, amounting to $51 \mathrm{~g}$ or $153 \mathrm{~g}$, depending on portion size condition. Participants also received a paper-pencil questionnaire with questions about the cookies (see Marchiori et al., 2011). They were told that they could eat as much of them as they wanted, as we had plenty of cookies available for all participants. Ten minutes later, the experimenter came back to remove cookies, water and rating form, and to tell them to switch back to the computer for some additional measures.

Participants reported on visual analog scales the tendency to clean their plate (Marchiori, Corneille, \& Klein, 2012), three ratings of the snacks they just had been served (how they would describe their satiety feeling, how the size of their serving of food would compare to their usual portion, and how they would rate the amount of food they were served for an afternoon snack) and the magnitude of three attentional foci during the afternoon snack: how much of their attention was focused on their eating, on their body sensations and on something else besides eating and body sensations. Moreover, participants completed several validated scales, including the Dutch versions of the Weight- and Body-Related Shame and Guilt scale (WEB-SG: Conradt et al., 2007) and a mindfulness trait measure to control for pre-existing differences in mindfulness between samples, the Five Facet Mindfulness Questionnaire (FFMQ: Baer, Smith, Hopkins, Krietemeyer, \& Toney, 2006). They also completed the Concern for dieting measure of the Restraint Scale (RS: Herman \& Polivy, 1980) and a measure of perceived self-regulatory success in dieting (PSRS: Fishbach, Friedman, \& Kruglanski, 2003). Table 1 gives an overview of the relationship between participant characteristics, their means and standard deviations. Finally, participants reported socio-demographic information (age, gender, height, weight, allergies and smoking) and their conjecture about the experiments. They were then thanked and introduced to the next experiment of the experimental session. All computerized measures were programmed using Qualtrics software (Qualtrics, Provo, UT). All analyses were performed with the statistical software IBM SPSS for Windows (release 19.0.0, 2011).

\section{Results}

Chi square analysis showed that gender did not differ significantly between all conditions, $\chi^{2}(3)=1.86, p=.6$, portion size, $\chi^{2}(1)=.00, p=1$, and intervention conditions, $\chi^{2}(1)=.71, p=.4$. An analysis of variance showed that there were no significant differences across conditions in participant characteristics (age, BMI, hunger, cookie taste, cookie appearance, mood, plate cleaning, FFMQ and PSRS: all $p>.26$ ). Only two variables differed between the four conditions, concern for dieting, $F(3,91)=3.79, p=.013$, $\eta_{p}^{2}=.11$, and guilt and shame (WEB-SG), $F(3,91)=3.69, p=.015$, $\eta_{p}^{2}=.11$. At a closer look, the latter effect (WEB-SG) was driven by the guilt scale, $F(3,106)=4.62, p=.004, \eta_{p}^{2}=.12$, rather than the shame scale, $F(3,106)=1.46, p=.23, \eta_{p}^{2}=.04$. Differences between conditions were present between portion size conditions, and absent between intervention conditions (all $p>.6$ ). Participants in the large portion condition reported higher guilt feelings and concern for dieting than participants in the small portion condition, $F(1,106)=12.89, p=.001, \eta_{p}^{2}=.11$, and $F(1,106)=10.24$, $p=.002, \eta_{p}^{2}=.09$, respectively. No significant difference was found for the shame scale, $p=.14$. Correlational analysis showed that guilt and concern for dieting correlate highly, $r(110)=.83$, $p<.001$. Hence, only concern for dieting was entered as a covariate in the remaining analysis, but results did not change when running analyses with guilt as a covariate. 


\section{Testing the main hypotheses}

Effects of portion size and mindfulness intervention on calorie intake An analysis of covariance in the General Linear Model, with portion size, mindfulness intervention, and their interaction as predictors of calorie intake revealed a main effect of portion size, $F(1,105)=19.70, p<.001, \eta_{p}^{2}=.16$. As Fig. 1 shows, participants who were served the larger portion of cookies consumed more calories than participants served the smaller portion $(M=222.77$, $S D=124.88$ vs. $M=139.53, S D=72.26$, respectively), with a difference of $83 \mathrm{kcal}$ or $60 \%$. Results did not change when controlling for participant and food-related characteristics. There was no main effect of the mindfulness intervention on calorie intake, $F(1,105)=.46, p=.5$. Contrary to our expectations, there was no interaction of mindfulness intervention and portion size on intake, $F(1,109)=.03, p=.87$. The mindfulness intervention did not reduce the portion size effect, as this was comparable in the control $(+78 \mathrm{kcal})$ and in the body scan condition (+86 kcal).

\section{Effects of mindfulness intervention on how hunger affects calorie intake}

We then added standardized hunger scores, and as expected, being hungry was associated with consuming somewhat more food overall, $F(1,105)=3.09, p=.08, \eta_{p}^{2}=.03$. More importantly, the mindfulness intervention moderated this effect, as shown by a significant interaction of hunger and intervention condition, $F(1,101)=4.13, p=.045, \eta_{p}^{2}=.04$. Analyses of the simple main effects showed that hunger had a significant effect on energy intake in the control condition, $F(1,53)=4.48, p=.04, \eta_{p}^{2}=.08$, but not in the body scan condition, $F(1,53)=.001, p=.98$. Figure 2 shows that in the control condition, being relatively more hungry increases energy intake by $67 \mathrm{kcal}$ compared to being less hungry; in the body scan condition this increase amounts only to $1 \mathrm{kcal}$. These effects were independent of portion size: portion size and hunger did not interact, $p=.29$, and there was no three-way interaction of portion size, mindfulness intervention and hunger, $p=.47$. Thus, the mindfulness intervention reduced the effects of hunger on unhealthy overeating, both when participants were presented with a large and a small portion of cookies.

\section{Ruling out alternative explanations}

Participants' ratings of the foods, the portion size and the audio recordings

Cookies were generally liked $(M=71.3, S D=17.5$; Range $=18$ 99) and food intake was correlated positively with cookie liking, $r(110)=.32, p=.001$. As expected, participants who were served the small portion of cookies reported their portion to be a lot smal-

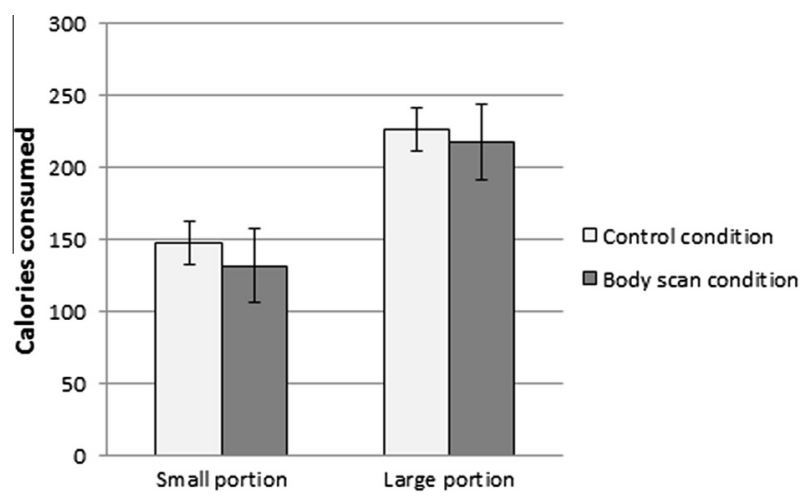

Fig. 1. Effects of portion size of food served (51 vs. $153 \mathrm{~g}$ of cookies) and condition (body scan vs. control audio tape) on calories consumed from cookies during the taste test. Error bars refer to the standard error of the mean.

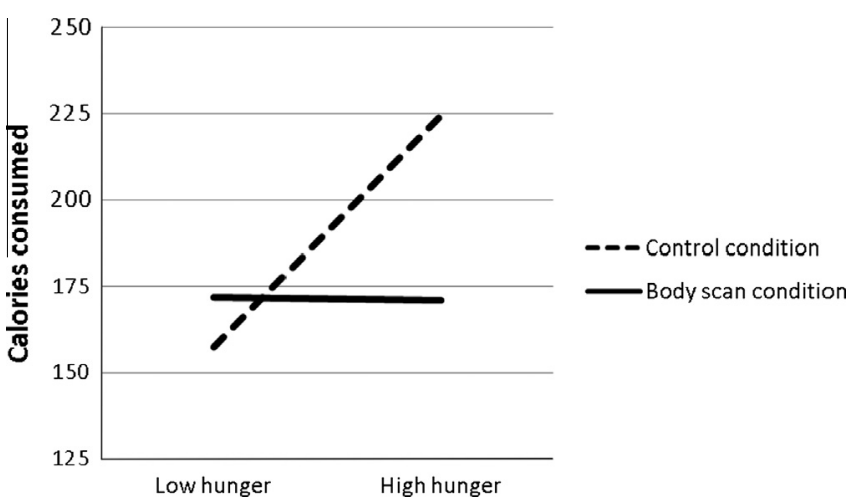

Fig. 2. Effects of self-reported hunger and condition (body scan vs. control audio tape) on calories consumed from cookies during the taste test. High and low hunger refers to one standard deviation above and below the mean of self-reported hunger, respectively (see Cohen, Cohen, West, \& Aiken, 2003).

ler and more appropriate than participants who were served the larger portion, $F(1,108)=28.74, \quad p<.001, \quad \eta_{p}^{2}=.21 \quad$ and $F(1,108)=23.28, p<.001, \eta_{p}^{2}=.18$, respectively. None of these ratings correlate significantly with energy intake though, $r(110)=.02$, $p=.87$ and $r(110)=.04, p=.66$. Interestingly, participants in both portion size conditions reported similar levels of comfort in their satiety, $F(1,108)=.38, p=.54, \eta_{p}^{2}=.003$. Entering these variables as covariates did not change significance of the main outcomes.

Participants in the control condition liked the audio recording ( $M=65.7, S D=21.5$ ) and rated the instructions to be clear $(M=72.8, S D=19.6)$. Similarly, participants in the mindfulness condition liked the body scan $(M=60.6, S D=28.8)$ and rated the instructions to be clear $(M=85.9, S D=17.8)$. To control for mood, we assessed how irritable, relaxed and enthusiastic participants felt on a scale from 0 to 100 . Results showed no significant differences between conditions (all $p>.2$ ). Participants reported low levels of irritability $(M=31.2, S D=23.4)$, relatively high levels of relaxation $(M=74.4, S D=21.4)$, and moderate levels of enthusiasm $(M=43.5, S D=20.5)$.

\section{Attentional foci}

Participants reported different levels of attention for different aspects of the eating situation (i.e., focus on eating, on their body sensations, or on something else), as shown in Table 2. A mixed analysis of variance was run with the intervention as a betweensubjects predictor and attentional focus (focus on eating; body sensations; something else than eating and body sensations) as within-subjects variables. This revealed a main effect of the attentional focus, $F(2,107)=18.06, p<.001, \eta_{p}^{2}=.14$, which was qualified by an interaction with condition, $F(2,107)=4.53, p=.036, \eta_{p}^{2}=.04$. As displayed in Table 2, participants in the control condition were mostly focused on eating and something else besides eating and body sensations, and less on body sensations. Participants in the mindfulness condition, however, made eating their primary focus, compared to something else and body sensations. Although this pattern is consistent with our reasoning about the effects of the mindfulness intervention, future research should attempt to examine more systematically how mindfulness affects the focus of attention during eating. Again, entering these variables as covariates did not change significance of the main outcomes.

Effects of water intake and thirst on calorie intake

Pre-study thirst influenced water intake, $F(1,108)=9.76$, $p=.002, \eta_{p}^{2}=.08$, which correlated positively with food intake, $r(110)=.21, p=.03$, and thirst, $r(110)=.20, p=.04$. However, no significant differences were observed between portion size and 
Table 2

Effects of condition (body scan vs. control audio tape) on self-reported attention on Body sensations, Eating, and Something else besides eating and body sensations, during the taste test (means $\pm S D$ ). Attention was measured separately for all three dimensions on a 100 -point visual analogue scale.

\begin{tabular}{llcl}
\hline & \multicolumn{2}{l}{ Focus of self-reported attention during the taste test } \\
\cline { 2 - 4 } & Eating & Body sensations & Something else than eating or body sensations \\
\hline Control condition & $66.5 \pm 20^{\mathrm{a}}$ & $45 \pm 27.4^{\mathrm{b}}$ & $63.8 \pm 23.7^{\mathrm{a}}$ \\
Body scan condition & $71.9 \pm 19.3^{\mathrm{a}}$ & $30.3 \pm 25.9^{\mathrm{c}}$ & $54.2 \pm 25.9^{\mathrm{b}}$ \\
\hline
\end{tabular}

Means that do not share superscripts differ at $p<.05$.

intervention conditions (all $p>.08, \eta_{p}^{2}<.03$ ). Hence, differences in energy intake cannot be attributed to thirst or water intake.

\section{Effects of gender on calorie intake}

Gender significantly influenced the amount of cookies participants consumed, $F(1,107)=14.66, p<.001, \eta_{p}^{2}=.12$. Male participants consumed more energy from cookies than female participants ( $M=238, S D=135$ vs. $M=158, S D=88$, respectively). However, gender did not interact with portion size or the intervention to influence energy intake (all $p>.6$ ). Moreover, given that gender was equally distributed across conditions, it cannot explain main or interaction effects of the experimental manipulations.

\section{Effects of time and location on calorie intake}

Cubicle and experiment day did not significantly influence energy intake, $F(5,100)=1.39, p=.23, \eta_{p}^{2}=.07$ and $F(8,100)=1.76$, $p=.09, \eta_{p}^{2}=.12$, respectively. However, time of day influenced intake, $F(2,106)=3.3, p=.04, \eta_{p}^{2}=.06$. Starting to eat at $4 \mathrm{pm}$ was associated with a higher energy intake $(M=211, S D=114)$ than starting to eat at $2 \mathrm{pm}(M=192, S D=120)$ or $3 \mathrm{pm}(M=147$, $S D=87)$. Contrast analysis showed that only the difference between 3 and $4 \mathrm{pm}$ was significant $(p=.016)$. Chi square analyses showed that these three day times were not differently represented in the portion size, $\chi^{2}(2)=1.96, p=.38$ and intervention conditions, $\chi^{2}(2)=.97, p=.62$. Moreover, time of day did not interact with portion size or intervention to influence energy intake (all $p>.15$ ). Therefore, time and location of the experimental session cannot explain main or interaction effects of the experimental manipulations.

\section{Effects of awareness of hypotheses}

Finally, analyses were re-run without participants whose report could suggest some knowledge about the hypotheses or goal of the study ( $N=16$; e.g., how satisfied about and aware of their body people are; whether the size of the portion affects what you eat; the relationship between the awareness of your body and your diet), but significance of the main findings did not change.

\section{Discussion}

The present study examined how a mindfulness-based intervention modulated the effects of portion size and of hunger signals on consumption of unhealthy snacks. Results showed that all participants ate more when served a larger compared to a smaller portion, independent of the intervention. However, after the brief mindfulness intervention, hunger was less likely to be translated into unhealthy snacking than in the control condition, independent of portion size. The latter finding is consistent with previous studies showing that mindfulness-based interventions modulate how hunger is translated into behavior, for example by preventing that hunger increases choices of unhealthy foods at a buffet (Papies et al., in preparation). In the present study, while intake was increased by hunger among participants in the control condition, a brief mindfulness exercise prevented participants from consuming more unhealthy cookies when hungry.
How can this effect be explained? Hunger typically promotes a motivation to approach high-energy food and to consume it, even without conscious awareness (Papies et al., in preparation; Seibt et al., 2007; Siep et al., 2009). When feeling hungry, food appears tastier and one's thoughts of eating it become more rewarding than in a satiated state (Papies et al., in preparation; Siep et al., 2009). Research has suggested that performing a body scan creates competing imagery that reduces cognitive capacity for the elaboration of craving imagery and thus desires to indulge in unhealthy food (Hamilton et al., 2013; Kemps \& Tiggemann, 2007). This is unlikely to explain the current findings, however, as participants completed the body scan before the taste test and before being exposed to the cookies, so that the body scan did not actually produce a working memory load during food exposure and eating. We therefore suggest that a different explanation is more likely.

Participants in the mindfulness condition were instructed to simply observe and to accept all thoughts and sensations in a nonjudgmental way. Adopting this perspective during the body scan may have carried over to the taste test, and may have made it easier for participants to refrain from reacting to their feelings of hunger (Keng, Smoski, \& Robins, 2011). As a result, they were less likely to quiet their hunger with attractive but unhealthy chocolate chip cookies. Supporting this reasoning, recent research has shown that both brief mindfulness manipulations as well as dispositional mindfulness reduce impulsive responding, which may help individuals to refrain from reacting to food and other temptations ( $\mathrm{Pa}-$ pies et al., 2012, in preparation; Peters, Erisman, Upton, Baer, \& Roemer, 2011; Westbrook et al., 2013). More specifically, participants in the present study may have entered the eating situation with an increased awareness of their thoughts, including rewarding thoughts about food (Papies, 2013), and with an accepting attitude that lets these thoughts arise and dissipate as mere mental events. This may have prevented them from acting on their impulses and quieting their hunger with attractive but unhealthy chocolate chip cookies (see also van Dillen \& Papies, in press). However, this last mechanism was not directly tested, and future studies might attempt to examine the experiences of participants in a mindfulness intervention more directly.

Contrary to our expectations, the mindfulness intervention did not reduce the portion size effect. Thus, although the body scan exercise clearly affected how participants reacted to internal hunger signals, it did not affect how they reacted to the external cue of portion size, eating more from a large than a small portion of cookies. This suggests that, at least among the current sample, reliance on external cues for how much to eat is not affected by awareness of internal signals of hunger or satiety. This is corroborated by another important finding of the current study, namely that the portion size effect was independent of participants' self-reported level of hunger. In other words, participants who were served a larger portion consumed more than participants served a smaller portion, independent of their current hunger, and even when the mindfulness intervention had increased awareness of body sensations.

Together, these findings may help to understand the mechanisms by which the portion size effect - a powerful yet poorly understood phenomenon (Kral, 2006; Wansink, 2004) - influences food intake: it does not just override internal cues, but may operate 
independently of these to influence food intake. Participants in the current study were influenced by both internal and external signals for eating behavior, depending on their salience, and these signals affected behavior in separate ways. Contrary to current assumptions (see for example Wansink, Payne, \& Chandon, 2007), internal and external influences on eating thus do not seem to be two ends of the same dimension, but rather two independent influences on eating behavior. Increasing awareness of internal signals may thus not reduce the effect of external signals. These findings also suggest that to prevent the powerful influence of the portion size, future research should examine strategies that target this effect directly through increasing awareness of the external cues for eating.

\section{Limitations}

One important limitation of the current study is that it was conducted among a rather homogeneous group of relatively lean and highly educated university students. In addition, only one type of food was offered in the snacking situation. Therefore, we cannot generalize to other populations or eating situations where multiple foods are present. In addition, we used a brief mindfulness training for non-meditators as our intervention, which differs from the extensive mindfulness training that other interventions typically use (see Grossman, Niemann, Schmidt, \& Walach, 2004). This approach increases experimental control, and it is informative that even a brief mindfulness intervention among non-meditators can prevent unhealthy eating when feeling hungry. However, the current experimental approach does not allow for a more comprehensive test of the effects of mindfulness in the more complex eating situations that we encounter in daily life. Future research should attempt to examine how integrating mindfulness exercises into daily life could affect eating in response to both internal and external cues among varied groups of participants.

\section{References}

Alberts, H. J. E. M., Thewissen, R., \& Raes, L. (2012). Dealing with problematic eating behaviour. The effects of a mindfulness-based intervention on eating behavior, food cravings, dichotomous thinking and body image concern. Appetite, 58, $847-851$.

Baer, R. A., Smith, G. T., Hopkins, J., Krietemeyer, J., \& Toney, L. (2006). Using selfreport assessment methods to explore facets of mindfulness. Assessment, 13, 27-45.

Bishop, S. R., Lau, M., Shapiro, S., Carlson, L., Anderson, N. D., Carmody, J., Segal, Z. V., Abbey, S., Speca, M., Velting, D., \& Devins, G. (2004). Mindfulness. A proposed operational definition. Clinical Psychology. Science and Practice, 11(3), 230-241.

Cohen, J. (1988). Statistical power analysis for the behavioral sciences (2nd ed.). Hillsdale, New Jersey: Lawrence Erlbaum Associates.

Cohen, J., Cohen, P., West, S. G., \& Aiken, L. S. (2003). Applied multiple regression/ correlation analysis for the behavioral sciences. Hillsdale, NJ: Erlbaum.

Conradt, M., Dierk, J. M., Schlumberger, P., Rauh, E., Hebebrand, J., \& Rief, W. (2007). Development of the Weight- and Body-Related Shame and Guilt scale (WEB-SG) in a nonclinical sample of obese individuals. Journal of Personality Assessment, 88, 317-327.

Cropley, M., Ussher, M., \& Charitou, E. (2007). Acute effects of a guided relaxation routine (body scan) on tobacco withdrawal symptoms and cravings in abstinent smokers. Addiction, 102, 989-993.

Dalen, J., Smith, B. W., Shelley, B. M., Lee Sloan, A., Leahigh, L., \& Begay, D. (2010). Pilot study. Mindful Eating and Living (MEAL). Weight, eating behavior, and psychological outcomes associated with a mindfulness-based intervention for people with obesity. Complementary Therapies in Medicine, 18, 260-264.

Dutch National Food Consumption survey 2007-2010 (VCP basisgegevensverzameling 2007-2010), part of the Dutch Food Consumption Survey, conducted by the RIVM, Bilthoven, contract number 2012-31.

Fishbach, A., Friedman, R. S., \& Kruglanski, A. W. (2003). Leading us not unto temptation. Momentary allurements elicit overriding goal activation. Journal of Personality and Social Psychology, 84, 296-309.

Grossman, P., Niemann, L., Schmidt, S., \& Walach, H. (2004). Mindfulness-based stress reduction and health benefits. A meta-analysis. Journal of Psychosomatic Research, 57(1), 35-43.

Hamilton, J., Fawson, S., May, J., Andrade, J., \& Kavanagh, D. J. (2013). Brief guided imagery and body scanning interventions reduce food cravings. Appetite, 17, $158-162$.
Herman, C. P., \& Polivy, J. (2005). Normative influences on food intake. Physiology E' Behavior, 86, 762-772.

Herman, C. P., \& Polivy, J. (1980). Restrained eating. In A. Stunkard (Ed.), Obesity (pp. 208-225). Philadelphia: Saunders.

Hill, J. O., \& Peters, J. C. (1998). Environmental contributions to the obesity epidemic. Science, 280, 1371-1374.

Kemps, E., \& Tiggemann, M. (2007). Modality-specific imagery reduces cravings for food. An application of the Elaborated Intrusion theory of desire to food craving. Journal of Experimental Psychology. Applied, 13, 95-104.

Keng, S.-L., Smoski, M. J., \& Robins, C. J. (2011). Effects of mindfulness on psychological health. A review of empirical studies. Clinical Psychology Review, $31,1041-1056$

Kral, T. V. E. (2006). Effects on hunger and satiety, perceived portion size and pleasantness of taste of varying the portion size of foods. Appetite, 46, $103-105$.

Kristeller, J. L, \& Wolever, R. O (2010). Mindfulness-based eating awareness training for treating binge eating disorder. The conceptual foundation. Eating Disorders. The Journal of Treatment \& Prevention, 19, 49-61.

Lozano, D. I., Crites, S. L., \& Aikman, S. N. (1999). Changes in food attitudes as a function of hunger. Appetite, 32, 207-218.

Marchiori, D., Corneille, O., \& Klein, O. (2012). Container size influences snack food intake independently of portion size. Appetite, 58, 814-817.

Marchiori, D., Waroquier, L., \& Klein, O. (2011). Smaller food item sizes of snack foods influence reduced portions and caloric intake in young adults. Journal of the American Dietetic Association, 111, 727-731.

Papies, E. K. (2013). Tempting food words activate eating simulations. Frontiers in Psychology, 4, 838.

Papies, E. K., Barsalou, L. W., \& Custers, R. (2012). Mindful attention prevents mindless impulses. Social Psychological and Personality Science, 3(3), 291-299.

Papies, E. K., Pronk, Keesman, M., \& Barsalou, L. W. (in preparation). The benefits of simply observing. Mindful attention reduces desire.

Papies, E. K., Potjes, I., Keesman, M., Schwinghammer, S., \& van Koningsbruggen, G. $M$. (in press). Using health primes to reduce unhealthy snack purchases among overweight consumers in a grocery store. International Journal of Obesity.

Papies, E. K., \& Hamstra, P. (2010). Goal priming and eating behavior. Enhancing self-regulation by environmental cues. Health Psychology, 29, 384-388.

Papies, E. K., \& Veling, H. P. (2013). Healthy dining. Subtle diet reminders at the point of purchase increase low-calorie food choices among both chronic and current dieters. Appetite, 61, 1-7.

Peters, J. R., Erisman, S. M., Upton, B. T., Baer, R. A., \& Roemer, L. (2011). A preliminary investigation of the relationships between dispositional mindfulness and impulsivity. Mindfulness, 2, 228-235.

Piernas, C., \& Popkin, B. M. (2010). Snacking increased among U.S. adults between 1977 and 2006. Journal of Nutrition, 140, 325-332.

Seibt, B., Häfner, M., \& Deutsch, R. (2007). Prepared to eat. How immediate affective and motivational responses to food cues are influenced by food deprivation. European Journal of Social Psychology, 37, 359-379.

Siep, N., Roefs, A., Roebroeck, A., Havermans, R., Bonte, M. L., \& Jansen, A. (2009). Hunger is the best spice. An fMRI study of the effects of attention, hunger and calorie content on food reward processing in the amygdala and orbitofrontal cortex. Behavioural Brain Research, 198(1), 149-158.

Simmons, W. K. Martin, A. \& Barsalou, L. W. (2005). Pictures of appetizing foods activate gustatory cortices for taste and reward. Cerebral Cortex, 15(10), 1602-1608.

The data for this paper was collected using Qualtrics software, Version 45132 of the Qualtrics Research Suite. Copyright (c) 2013 Qualtrics. Qualtrics and all other Qualtrics product or service names are registered trademarks or trademarks of Qualtrics, Provo, UT, USA. <http://www.qualtrics.com>.

Van de Veer, E., vanHerpen, E., \& van Trijp, J. C. M. (2012). Body and mind. How mindfulness enhances consumers' responsiveness to physiological cues in food consumption. Advances in Consumer Research, 39, 603-604.

van Dillen, L. F., \& Papies, E. K. (in press). From distraction to mindfulness. Psychological and neural mechanisms of attention strategies in self-regulation. In G. Gendolla, M. Tops, S. Koole (Eds.), Biobehavioral foundations of selfregulation. Springer.

Wansink, B. (2004). Environmental factors that increase the food intake and consumption volume of unknowing consumers. Annual Review of Nutrition, 24, $455-479$.

Wansink, B. (2006). Mindless eating. Why we eat more than we think. Random House LLC.

Wansink, B., \& Kim, J. (2005). Bad popcorn in big buckets. Portion size can influence intake as much as taste. Journal of Nutrition Education and Behavior, 37, 242-245.

Wansink, B., Painter, J. E., \& Lee, Y. K. (2006). The office candy dish. Proximity's influence on estimated and actual consumption. International Journal of Obesity, 30, 871-875.

Wansink, B., Payne, C. R., \& Chandon, P. (2007). Internal and external cues of meal cessation. The French paradox redux? Obesity, 15, 2920-2924.

Westbrook, C., Creswell, J. D., Tabibnia, G., Julson, E., Kober, H., \& Tindle, H. A. (2013). Mindful attention reduces neural and self-reported cue-induced craving in smokers. Social Cognitive and Affective Neuroscience, 8, 7384.

World Health Organization (2010). Obesity and overweight. Retrieved from the WHO website on Sept 15, 2010. <http://www.who.int/dietphysicalactivity/ publications/facts/obesity/en/>. 